\title{
Prefácio à edição francesa de Os Nuer ${ }^{1}$
}

\author{
LOUIS DUMONT \\ Ecole de Hautes Etudes en Sciences Sociales | Paris, França \\ tradução BEATRIZ PERRONE MOISÉS iD \\ Universidade de São Paulo | São Paulo, SP, Brasil \\ perrone@usp.br
}

DOI 10.11606/issn.2316-9133.v30i2pe191856

Sem mencionar os artigos, muitas vezes retomados ou resumidos nos livros subsequentes, Evans-Pritchard dedicou aos Nuer três obras - esta é a primeira delas. A segunda, mais breve, é dedicada ao parentesco, a terceira à religião. Esta primeira é a mais famosa. Pelo que contém, e talvez mais ainda pela influência que exerceu, este livro por si só pode dar ao leitor uma ideia suficiente de toda uma literatura, ou de toda uma escola, poderíamos dizer. O fato é que os Nuer, de 1940, e os Azande (1937) inauguraram um modo de consideração sociológica de sociedades tribais que floresce há um quarto de século, principalmente do outro lado do Canal da Mancha, e que cobre grande parte do que é designado como antropologia social. Os Nuer são o arquétipo da teoria dos grupos de filiação unilinear ("descent groups") e da teoria dos grupos políticos. São também, e ainda mais, o modelo longamente venerado e ainda ativo de todo antropólogo inglês quando busca dar uma forma definitiva a seu trabalho. Acrescentemos que a reflexão de Evans-Pritchard, que se enraíza principalmente na tradição britânica, nutre-se de sociologia francesa. Sob sua égide foram publicadas, nas duas últimas décadas, graças a Rodney Needham e outros, várias traduções de obras de Mauss, Durkheim e Hertz. Sabendo, ademais, que Evans-Pritchard escreve com a elegância que nasce da precisão e da clareza, conclui-se que uma tal obra não precisa de prefácio para ser apresentada ao leitor francês.

Eis que, no entanto, pedem-no a alguém que, tendo dado aulas em Oxford por quatro anos e lá obtido boa parte de sua formação científica, sente pelo autor de Os Nuer uma profunda admiração e se orgulha de ser seu amigo. Alguém que não pode se esquivar dessa perigosa honra - que enfrente, portanto, a questão do lugar da presente obra na antropologia inglesa, tentando não se afastar demais dos interesses gerais do leitor.

$* * *$

\footnotetext{
${ }^{1}$ In: E. E. Evans-Pritchard. Les Nuer. Description des modes de vie et des institutions politiques d'un peuple nilote. Paris, Gallimard, 1968, pp. i-xviii. Foi omitida nesta tradução uma primeira parte (dois parágrafos), em que Dumont fala de traduções de obras essenciais (como essa) para o francês.
} 
O subtítulo anuncia o duplo objeto do livro: de um lado, o meio e o modo de vida que impõe; do outro, um conjunto de conceitos e mecanismos em nada derivados do meio, que instauram a "anarquia ordenada" na qual o autor vê o "sistema político" dos Nuer. O contraste entre os dois estudos é tão marcado que à primeira vista poderíamos ficar tentados a dizer que o livro possui duas vertentes, uma materialista e a outra idealista. Como o leitor tem a liberdade de enfatizar uma ou outra, talvez seja essa uma primeira razão da popularidade do livro entre os especialistas. Poderíamos até nos perguntar se essa heterogeneidade não seria a marca de uma virada, uma conversão, no itinerário intelectual do autor. Percebe-se, com efeito, que o livro não foi começado e terminado no mesmo estado de espírito, e basta para tanto comparar o fim da introdução e o último parágrafo da conclusão. Na verdade, estamos num plano técnico: consciente dos limites de uma pesquisa cujas dificuldades aponta, o autor quis limitar sua ambição, oferecendo uma "contribuição à etnologia", e não um "estudo sociológico detalhado". Porém, de modo aparentemente paradoxal, a - muito relativa - pobreza de seu material levou-o a desenvolver a análise do sistema dos grupos territoriais e outros, de modo que a conclusão começa admitindo "uma breve incursão na teoria sociológica” e reconhece mais adiante ter contribuído para o progresso teórico ao deixar para trás a consideração de "massas sociais e de uma suposta relação entre essas massas", expressão cujo alcance preciso veremos adiante.

Perguntado, o autor nega ter evoluído ao longo da escrita de Os Nuer, explica que quis implantar aquele povo solidamente em seu modo de subsistência e no contexto de suas determinações naturais antes de abstrair o aspecto linhageiro-político de sua vida. É o que deve fazer um etnólogo, era o que Mauss nos ensinava aqui, insistindo na importância dos traços materiais da vida social, de tudo o que pode ser inventoriado, contado, medido, desenhado. Só mesmo uma sobreavailação ingênua das possibilidades da análise - ainda que frequente em nossos dias - pode levar a descuidar da atenção a esse quadro mais amplo, às amarras visíveis: são apoios sólidos para suas mãos desajeitadas e cercas de contenção dos devaneios de sua imaginação.

De resto, vejamos a admirável composição desse livro, seu movimento interior. Há claramente uma dualidade em seu princípio, mas é com naturalidade que o autor, inicialmente preocupado em delimitar, aprofundar e esgotar os determinantes naturais da vida dos Nuer, se vê progressivamente compelido a outros tipos de determinantes. O que chamaríamos de meio, de um lado, e as relações humanas, do outro, dominam em estado puro, no início e no fim do livro respectivamente, e o livro é uma espécie de continuum em que a primeira variável vai perdendo força à medida em que se afirma a segunda, em seus enredamentos recíprocos. O capítulo sobre tempo e espaço faz a passagem. Nele vemos justapostos, por exemplo, um tempo ecológico regido pelo ritmo das estações e a "dupla morfologia" resultante - para retomar uma expressão de Mauss: dispersão em aldeias na estação das chuvas, reunião progressiva ao redor dos pontos de água na estação seca - e um "tempo estrutural", isto é, (puramente) social. O sistema político, na medida em que é um sistema de grupos territoriais, também está estreitamente relacionado ao meio, ao passo que o sistema de linhagens só tem com ele uma relação indireta. Diante disso, o que pensar da 
crítica segundo a qual a "estrutura social" seria aqui arbitrariamente recortada, como um objeto em si, dos aspectos materiais da vida social? ${ }^{2}$ (cf. Leach, 1961: 305) Parece-me, ao contrário, que Evans-Pritchard assinalou com a maior das finezas a multiforme complementariedade entre a face interna e a face externa da sociedade: relações entre pessoas e relações entre pessoas e seu meio.

Para nos ajudar a apreciar corretamente o lugar de Os Nuer na antropologia social inglesa, temos a sorte de dispor de um testemunho privilegiado, a que recorrerei tanto quanto possível. David Pocock dedica a isso algumas páginas de um pequeno livro, Social Anthropology, publicado em 1961, e o testemunho é ainda mais precioso na medida em que foi escrito em Oxford e a passagem que nos interessa teve certamente a aprovação do próprio Evans-Pritchard em suas grandes linhas. Lembremos inicialmente que a antropologia social inglesa se constituiu sob a égide teórica de A. R. Radcliffe-Brown, a quem Evans-Pritchard sucedeu em Oxford, em 1950. David Pocock (1961) caracterizou muito bem a antropologia radcliffe-browniana, e peço ao leitor que perdoe a longa citação, que é indispensável:

Para toda uma geração de antropólogos sociais, principalmente na Inglaterra, o objetivo da pesquisa de campo (fieldwork) parece ter sido buscar os fatores de integração social, o que os levou a círculos viciosos. A sociedade é um mecanismo adaptativo [expressão de Radcliffe-Brown na qual o autor insiste anteriormente] e mantém sua harmonia interna como se supõe que um organismo vivo o faça. Tal harmonia se manifesta nas relações entre as instituições e entre as instituições e as crenças gerais da sociedade; a função de uma parte, por conseguinte, é o seu papel na manutenção de tais relações.

No que diz respeito à organização formal, essa função era dada na descrição das relações: o parentesco mantinha a solidariedade do clã, o chefe se tornava "um símbolo da solidariedade da tribo", a função das assembleias era reafirmar a solidariedade dos que nelas se reuniam. $\mathrm{O}$ problema eram os aspectos da vida social que, como notara Durkheim, não são imediatamente redutíveis a "grupos e relações entre grupos". Se Durkheim tinha ampliado o conceito de sociedade, aqui, ao contrário, tais fenômenos eram explicados na medida em que podiam ser entendidos como fatores integradores em operação na integração dos grupos. A religião, as diversas formas de arte - incluindo literatura oral, danças e mitos -, as cosmologias de povos primitivos podiam ser vistas como expressão, símbolo e ênfase de determinados valores, importantes para a

\footnotetext{
${ }^{2}$ Cf. Leach (1961: 305): "na prática, as partes do livro são autônomas e cada uma pode ser compreendida independentemente do restante”.
} 
manutenção da família ou da tribo, e fora disso havia pouca coisa a dizer a respeito. E se pouco se podia dizer é porque não havia linguagem para dizê-lo. Já que a matéria da antropologia social era o estudo da estrutura social, e essa consistiria exclusivamente na descrição de grupos e das relações entre eles, a sociologia de Radcliffe-Brown, à diferença da de Durkheim, não fornecia conceitos para a consideração sociológica dos fenômenos em si (Pocock, 1961: 62-63).

Os Nuer se sobressai em relação a esse funcionalismo: nada aqui de "integração social". Ao contrário, encontramos na conclusão um questionamento, breve e discreto, mas categórico, dos "grupos e relações entre grupos". Já o encontramos, mas vamos novamente citá-lo, a partir de Pocock: "A antropologia social da atualidade se satisfaz com conceitos sumários - tribo, clã, classe de idade etc. - que representam massas sociais, e uma suposta relação entre tais massas. A ciência não pode avançar com esse baixo grau de abstração, se é que se pode falar em abstração; é preciso empregar conceitos que designem relações, definidos em função de situações sociais, e as relações entre tais relações”.

Nosso guia insiste em seguida nas "relatividades da linguagem dos Nuer" (:74). A palavra cieng, "casa", "lar" (home) ou "residência" assume sentidos diferentes conforme a situação em que é pronunciada. Como entre nós, a pergunta “de onde você vem?” pode ser respondida, a depender do caso, por França, Paris, 9eme arrondissement ${ }^{3}$, rua Lafayette etc. De modo mais amplo, Evans-Pritchard generalizou a percepção de um elemento de experiência a partir de seu contexto, sincrônico ou não, e isso desde sua monografia anterior sobre a feitiçaria entre os Azande. Essa é talvez sua principal contribuição; de todo modo, é a menos contestada de todas. "As palavras e os objetos ou relações a que remetem devem ser compreendidos em relação, como um sistema dotado de sentido (a meaningful system)" (Pocock, 1961: 75). Passando de Radcliffe-Brown para Evans-Pritchard, encontramos, portanto, um "movimento da função para a significação" (Ibidem: 76), e o exegeta marca aqui a aproximação com Lévi-Strauss. Aproximação talvez um tanto rápida, à qual precisaremos voltar, mas fundada em parte, como Pocock mostra citando uma passagem em que fica claro que a "estrutura" não é mais a "estrutura social” de Radcliffe-Brown, mas algo bem diferente, uma realidade mental: "Sublinho essa característica da distância estrutural desde esta primeira etapa, porque é necessário compreendê-la para acompanhar na sequência a descrição dos diversos grupos sociais. Uma vez entendida essa noção, as contradições aparentes de nossa exposição aparecerão como contradições na própria estrutura, de que são, na verdade, um atributo."

Essa passagem "da função para a significação", que, como mencionei, representa com certeza o que Evans-Pritchard crê ter efetuado, pelo menos retrospectivamente, constitui uma verdadeira revolução, e é espantoso que tenha sido apresentada com tanta discrição. Discrição evidentemente deliberada, esclarecida talvez pela modéstia que encontramos particularmente na introdução. O que Pocock acrescenta é importante para a história da

\footnotetext{
${ }^{3}$ N.T.: Bairro parisiense. A cidade de Paris é dividida em arrondissements numerados de 1 a 20.
} 
disciplina na Inglaterra: "A recusa do autor (de Os Nuer) de explicitar a mudança de orientação tinha vantagens táticas" (:79): nem tempestade nem poeira levantada, mas na continuidade mantida em aparência, a intrusão vitoriosa - a influência do livro seria testemunha disso - do sentido que os atores dão ao que fazem. Em contrapartida, havia uma desvantagem: o organicismo de Radcliffe-Brown não tinha sido diretamente questionado e as noções de equilíbrio e harmonia social iriam continuar dominantes como princípios explicativos. Foi apenas em 1950, em sua Marett Lecture, que Evans-Pritchard (2021 [1950]) detonou a bomba preparada havia pelo menos dez anos: rejeitou a pretensão da antropologia social de se colocar como ciência natural, acusou o positivismo, tirou as consequências, agora de forma radical, da passagem das leis às estruturas. A maior parte dos colegas que tinham aplaudido Os Nuer ficaram escandalizados. O cisma com Radcliffe-Brown estava consumado.

A polêmica desencadeada pela Marett Lecture apresenta, em contraste com o prestígio que Os Nuer continuou tendo e a influência que continuou exercendo no meio, uma questão de ordem geral em relação ao livro: seria possível distinguir nele uma parte coletiva e uma parte pessoal, isto é, uma parte que corresponderia às tendências predominantes da antropologia inglesa e uma outra que, ao contrário, seria própria do autor, talvez até oposta às tendências do meio? À primeira poderíamos consequentemente atribuir determinantes ou concomitâncias sociais diretas.

Não é difícil responder à pergunta de modo aproximado. No essencial, a teoria dos grupos unilineares e do sistema político foi adotada, retomada e continuada; na verdade, essas pesquisas tornaram-se o núcleo central da antropologia social inglesa, enquanto o aspecto propriamente ou rigorosamente estrutural de Os Nuer, ao contrário, não se enraizou realmente na Inglaterra, o que naturalmente não quer dizer que não houve nenhum empréstimo ou que Evans-Pritchard não teve nenhum adepto.

Para distinguir esses dois aspectos com alguma verossimilhança seria logicamente preciso começar pela posteridade de Os Nuer, de que o aspecto não-coletivo apareceria como resíduo. Por comodidade, procederei ao inverso. É o aspecto estrutural que representa aqui o aporte propriamente pessoal e original de Evans-Pritchard. Considerando o que leitores franceses conhecem a esse respeito, é preciso fazer um ajuste delicado. Notamos acima, acompanhando Polock, as "relatividades da linguagem" e de modo mais geral de significado de acordo com a situação ou contexto. O que caracteriza Os Nuer é a aplicação desse método aos grupos sociais, territoriais ou "políticos", grupos de filiação patrilinear: sou membro do grupo $A$ em situação que o oponha a $B$, mas em outra situação, em que se oponham dois segmentos (de primeira ordem) de A, ou A1 e A2, já não sou membro de $A$, mas de $A 1$, e assim por diante pelos segmentos de menor ordem. Os grupos dos diversos níveis existem virtualmente o tempo todo, mas só se manifestam de modo alternado, de acordo com as circunstâncias. A realidade permanente é a tendência contraditória à fissão e à fusão. Não é 
possível apreender grupos unilineares permanentes como "pessoas jurídicas"4 ligadas a um bem compartilhado, "corporate".

A percepção é evidentemente estrutural, mas uma questão fica implícita no termo "oposição" que acabo de empregar: em situações concretas, trata-se em geral de oposições de fato, de conflito, como na vingança de sangue (feud em inglês). Evans-Pritchard parte de "grupos e relações entre grupos" para relativizar os grupos e mostrar que estes existem a partir de suas relações. Mas é evidente que, na mente do autor, essas oposições de fato estão apoiadas em oposições conceituais, oposições no sentido estruturalista. Um nuer "se identifica com uma comunidade local e, ao fazê-lo, distingue-se de outras comunidades da mesma espécie" [diz Evans-Pritchard em Os Nuer]. Veja-se também a citação acima, que afirma que a "contradição" deve ser encarada como característica da própria estrutura. $\mathrm{O}$ autor de fato descobriu por conta própria o estruturalismo, sem empréstimos diretos, como foi o caso em desenvolvimentos contemporâneos, a disciplinas vizinhas (fonologia, Gestalttheorie). O fato é ainda mais digno de nota ne medida em que a posteridade de Os Nuer mostra que nisso Evans-Pritchard não expressava a corrente majoritária da antropologia social inglesa e, muito pelo contrário, permaneceria largamente incompreendido em sua convicção profunda de que as "estruturas" se opõem às "leis" da vida social a cuja descoberta se dedicavam ainda quase todos os seus contemporâneos. Veremos mais adiante, no entanto, que não é impossível detectar em nosso autor, em estado subjacente, uma orientação similar à de seus futuros oponentes.

Em relação aos ensinamentos que Mauss nos dispensava até 1939, encontramos em Os Nuer uma série de diferenças. Onde Mauss falava ainda em "organização políticodoméstica", Evans-Pritchard distingue "sistemas" distintos, em particular o dos grupos territoriais e políticos e o dos grupos de filiação unilinear (clãs e linhagens). Foi no campo da política que o autor de Os Nuer expressou mais claramente sua escola e sua época. Nesse campo, a obra apresenta uma proposta de extensão da categoria do político a sociedades que não possuem um órgão político diferenciado (nem precisa ser um rei): há ordem num determinado território sem que haja comando, uma "anarquia ordenada". Retrospectivamente, Os Nuer aparecem como ponto de partida de uma vasta literatura dedicada ao aspecto político de sociedades tribais. Tal literatura extrapola de muito o ponto de vista inicial, num duplo movimento: de um lado, a consideração da política vai-se estendendo na medida em que se alarga a definição do "político" e, do outro, esta análise em particular tende a tornar-se cada vez mais autônoma em relação ao quadro geral da antropologia social. Aquilo que em Evans-Pritchard não passava ainda de um subsistema do sistema social global entre outros parece tornar-se em autores recentes uma especialidade, uma "antropologia política" que sacrifica a referência à sociedade global. Embora não se possa

\footnotetext{
${ }^{4}$ N.T.: "Personne morale" no original.
} 
ver tais desenvolvimentos em germe em Os Nuer, tendo em vista o significado histórico da obra, é legítimo refletir sobre o sentido e o interesse do movimento como um todo.

Aqui, como alhures, cabem considerações de natureza fundamental e outras mais superficiais. Para julgar o valor definitivo de uma determinada orientação em antropologia social, podemos nos perguntar em que medida ela de fato trabalha para unificar as diferenças salientes entre sociedades "primitivas" e aquelas mais complexas que podem ser chamadas de "tradicionais", de um lado, e do outro o tipo moderno de sociedade. Estamos aqui bem próximos do espírito de nosso autor (cf. Evans-Pritchard, 1951: 22) e Mauss (1986: 269-95) insistia nisso desde 1897: não basta adotar, mesmo que modificadas, categorias modernas ou ocidentais, trata-se antes de subsumir os modos de pensamento dos dois universos em categorias comuns. No presente caso, o problema se manifesta indiretamente na dificuldade de definir o campo, na impossibilidade - até hoje - de um acordo entre os especialistas a respeito dos fenômenos políticos em geral. Os adeptos desse modo de consideração postulam em suma que se nós temos "político", todas as sociedades devem ter. Melhor seria buscar as equivalências entre o que nós incluímos em determinadas categorias e o que noutros lugares entra em outras categorias ou tem uma existência não-categórica. É isso, aliás, que é feito em larga medida em Os Nuer, onde o sistema político é definido como sistema de "grupos territoriais”, isto é, de grupos nomeados pelos Nuer, ainda que estruturais, cujo caráter territorial o antropólogo optou por ressaltar. Em outras palavras, ele não está certo de que a dimensão política, pelo mero fato de as sociedades modernas a distinguirem claramente, seja uma boa dimensão comparativa. Na verdade, a priori isso é improvável, já que muitas sociedades fazem diferente. Eu defenderia inclusive que isso já foi demonstrado a posteriori como falso, pela experiência, mas essa é uma posição extrema que muitos recusariam.

Como explicar, então, o sucesso da temática política entre antropólogos? Arrisco a hipótese de que se enraiza na mentalidade do antropólogo enquanto moderno, e não se deve levar isso a mal, pois nesta disciplina esse tipo de subjetividade coletiva não pode e não deve ser desconsiderado. Não se trata de psicologia no nível das boas intenções, mesmo que elas tenham um papel, na medida em que escolhemos insistir sobre o que pode aproximar de nós as sociedades e pessoas que costumamos estudar, em vez de acentuar aquilo que à primeira vista parece aumentar a distância, como por exemplo práticas mágicas. Trata-se do fato de nós, modernos, termos profundamente implantado em nós uma ideia de humano que tendemos a conservar e aplicar em qualquer ocasião. A temática política serve de apoio a esse modo de pensar, ao passo que outras a colocariam em questão. Essa é a explicação que proponho, por minha conta e risco.

Esclareço brevemente. A comparação entre sociedades modernas e não-modernas gira em torno de duas configurações de valores opostas. Para nós, o homem é o indivíduo o sujeito individual em si mesmo; para as sociedades não-modernas, é em grande medida é à sociedade, ao homem coletivo, que o sujeito particular é referido. Chamo a primeira mentalidade de "individualismo" e a segunda de "holismo". A passagem, a transição que o antropólogo deve efetuar entre elas não é fácil, e do mesmo modo que os anglo-saxões sobretudo acusaram Durkheim de ter reificado o fato da vida social das pessoas ou indivíduos ao falar em "consciência coletiva", teríamos razões para acusá-los de fazer como se essa 
profunda diferença de valores não existisse e de ver por toda parte indivíduos no sentido moderno do termo, gente imbuída de valores de liberdade e igualdade, ignorando ou inferiorizando valores como ordem, interdependência, hierarquia, subordinação, ou subordinando - como predomina entre nós - a tradição à "racionalidade".

Ora, quando se considera a filosofia política ou a ciência política modernas, salta aos olhos uma característica que costuma passar despercebida, de tão óbvia que parece. O campo do político é definido por características específicas: assim, a definição Estado de Max Weber (monopólio legítimo de força num determinado território) é geralmente adotada como base pela antropologia inglesa, pelo menos no início. Mas o ponto de vista político corresponde ainda, ou também, a algo diferente: não mais a consideração de certos fatos sociais que apresentam características distintivas, mas da totalidade do social, do ponto de vista do indivíduo. Isso está bem claro em Hobbes, Rousseau e Hegel (cf. Dumont 1965: 38; 57). Olhando bem, vê-se que isso fica geralmente implícito quando o primeiro ponto de vista é privilegiado e torna-se explícito na antropologia mais recente. É como se para o individualismo moderno só fosse possível apreender a totalidade social a partir da categoria do político. (Isso só é verdade, obviamente, se excluirmos a sociologia, ou antes um tipo de sociologia, mas vale para a mentalidade comum).

Sendo assim, é evidente que o político deva atrair antropólogos modernos, particularmente anglo-saxões, se não estiverem preparados para enfrentar o desafio que as sociedades não-modernas lançam à sua própria consciência - à sua cara individualidade. Escolhe-se a dimensão política - ou quem sabe a econômica - e quaisquer que sejam as dificuldades que se encontrar, sempre se terá diante de si, em qualquer lugar, indivíduos operando escolhas, "maximizando" suas vantagens, "manipulando" situações conforme as instituições tradicionais permitem. Ainda que viva desconfortavelmente nas antípodas, não abrirá mão do conforto intelectual. Quando a pesquisa de campo intensiva se estabeleceu, zombaram dos antropólogos da época anterior, que se contentavam em trabalhar de segunda mão e não saíam de suas poltronas. Seria possível dizer de colegas nossos que quanto mais enfatizam a dimensão política menos se afastam do que poderíamos chamar de sua poltrona metafísica, mais confortavelmente permanecem instalados no erro que dominou o século XIX, quando o individualismo moral e político foi confundido com uma descrição da vida dos homens em sociedade.

Aqui estamos longe da obra de Evans-Pritchard, que provavelmente recusaria grande parte dos trabalhos subsequentes, e não se trata, evidentemente, de atribuir a ele qualquer responsabilidade pelo que se seguiu. A verdade é que Os Nuer abriu um caminho no qual se precipitou uma tendência da antropologia contemporânea, que muito se distanciou de seu modelo e ganhou força na medida em que é - se concordarem com meu ponto de vista menos fundamental. Fato que por sua vez coloca uma questão: como foi possível fazer esse uso de Os Nuer? Retrospectivamente, a própria diferenciação de um "sistema político" parece ter sido o gatilho. O que para Evans-Pritchard era o início de uma análise mais precisa e mais sistemática do que a mera consideração "das massas e das relações entre essas massas" propiciou um desenvolvimento em que o pesquisador moderno não coloca suficientemente em questão seus próprios pressupostos. Arriscando outra opinião, mas que desta vez creio 
ter justificado algures, pode-se sem dúvida distinguir uma dimensão territorial ou um atributo territorial de certos grupos, mas também se pode, sem nada tirar do verdadeiro conteúdo de Os Nuer, creio, evitar fazer desse atributo uma substância, o princípio de um sistema sui generis. Neste caso, restaria apenas um sistema em vez de dois: um sistema de grupos de filiação provido de uma dimensão territorial. ${ }^{5}$

A posteridade de Os Nuer no que diz respeito ao sistema de grupos de filiação unilinear (descent groups) é diversa à primeira vista. Vimos nosso autor dedicado, afinal, a relativizar tais grupos. Ora, imediatamente depois, a tendência oposta, de reificar e solidificar, na linha de Radcliffe-Brown, reafirmou-se vigorosamente com Meyer Fortes. Além disso, percebe-se em Meyer Fortes um outro desenvolvimento, este original, na relação entre parentesco e grupos de filiação. Voltemos a Radcliffe-Brown. Naturalmente, ele conhece a existência de grupos de filiação unilinear, clãs ou linhagens, e para ele esses grupos fazem parte integrante dos sistemas de parentesco. Em Evans-Pritchard, o sistema desses grupos se emancipa do sistema global de parentesco e se constitui à parte: isso se fundamenta nas concepções dos próprios Nuer, que distinguem o parentesco familiar (gol), o parentesco "cognático" em geral (mar) - em que devem ser incluídas todas as relações individuais de parentesco externas à família e próximos - e o parentesco agnático longínquo (buth), que se aplica apenas a pessoas de linhagens diferentes. Isso basta para justificar que o sistema dos grupos de filiação não apareça como um sub-sistema interno ao sistema global de parentesco, mas como um sistema distinto das relações individuais de parentesco que, elas, se apresentam como centradas num sujeito abstrato hipotético, um Ego, como se diz? O fato é que na sequência, em Meyer Fortes (1953: 30), o sistema de grupos de filiação é subordinado ao das relações individuais de parentesco. Como diz ele, a filiação unilinear (descent) "liga o aspecto exterior, político e legal (...) e o aspecto interior ou doméstico, em que... o parentesco ganha mais peso". Ou seja, o sistema de grupos de filiação, que no começo se emancipara do sistema global de parentesco, é agora apresentado como hierarquicamente superior à rede individual das relações de parentesco. Não cabe aqui discutir essa tese metodologicamente bastante curiosa. É possível apenas chamar a atenção para seu aspecto algo metafísico: onde no começo havia um sistema de relações (relações individuais de parentesco centradas num sujeito e, em Evans-Pritchard, relações entre grupos que levam sucessivamente à existência de grupos de determinados níveis de segmentação), agora temos substâncias coletivas, grupos unilineares sólidos, "corporate", que se sobrepõem às relações. $\mathrm{O}$ aspecto relativizante e relacional de Os Nuer foi expurgado. A visão radcliffe-browniana de "grupos e relações entre grupos" é reafirmada, ou melhor, triunfa, reduzindo a uma

\footnotetext{
${ }^{5}$ Uma solução inversa, que reduz unilinearidade e segmentação a uma expressão do aspecto político foi, a meu ver, proposta por M. G. Smith (“Os segmentary lineage systems”, Journal of the Royal Anthropological Institute, t. 86-2, 1956, p. 39-80, especialmente p. 64ss), que escreve, por exemplo: "A linhagem é parentesco governamental e ideológico" (p. 71, destaque meu).
} 
posição subordinada o campo em que a relação reinava pelo menos desde Morgan, o das "relações de parentesco" no sentido corrente da expressão. Além disso, visto que os "corporate groups" em plena apoteose são no fundo concebidos como indivíduos coletivos, reencontramos aqui a mesma tendência que vimos no campo do político: o antropólogo desenvolve todas as sutilezas do mundo, mas não se livra de sua ancoragem metafísica pessoal, não sai da concepção de pessoa de sua própria sociedade.

Vemos assim que, em matéria de grupos de filiação, se nosso autor abriu mais essa via que outros explorariam com dedicação, a inspiração própria de Evans-Pritchard, estrutural e relacional, deparou-se na Inglaterra com uma oposição ou incompreensão notável. Resta-nos justificar brevemente nossa afirmação de que, mesmo nos Nuer, em estado subjacente, essa tendência coletiva, oposta à conquista pessoal própria do autor, está presente. Examinemos seus pontos de partida. O que é um sistema? É um "conjunto de relações entre grupos". A estrutura, definida inicialmente de modo minimalista como o que perdura numa sociedade, difere na verdade pouco de um sistema: é dito que um conjunto de relações pessoais não é uma estrutura porque, não envolvendo grupos, não é permanente. Somos obrigados a notar um paradoxo nessa dupla ênfase em grupos e relações. As relações de parentesco, que também transcendem o efêmero sujeito individual, não acedem à mesma dignidade dos grupos e relações entre grupos como sistema de grupos. Naturalmente, encontramo-nos aqui no ponto de partida, por assim dizer, e o autor irá se esforçar por destruir tais grupos enquanto substâncias e mostrar sua "relatividade estrutural”. Era natural partir do que era central em Radcliffe-Brown, e cabe pensar aqui na preocupação tática evidenciada por David Pocock. Isso não basta, pois a decisão de isolar a dimensão política (ou territorial) corresponde evidentemente ao a priori substancialista de Radcliffe-Brown. Há certamente aqui, de certo modo na raiz de Os Nuer, uma certa ambiguidade. Vimos que a posteridade da obra se encarregou de afastá-la: hoje fica claro, para mim em todo caso, que a perspectiva realmente estrutural não tem o que fazer com a sobrevalorização do político e que, inversamente, a consideração privilegiada do político, tal como se manifestou no conjunto, funda-se definitivamente na reintrodução, subreptícia ou pretenciosa, mas sempre ingênua, numa matéria em que este Livro, como outras obras-mestras, mostrou-nos o caminho oposto, o da relação. ${ }^{6}$

\section{Referências bibliográficas}

DUMONT, Louis. 1965. The modern conception of the individual: Notes on its genesis. Contributions to Indian sociology 8: 13-61

\footnotetext{
${ }^{6}$ Para outras observações sobre Os Nuer e a escola inglesa, ver minha Introduction à deux théories... ParisHaia, Mouton, 1971 (École Pratique des Hautes Études, VIa sessão, Les Textes Sociologiques, VI). Este prefácio foi publicado em tradução da professora Mary Douglas e de James Douglas em Studies in Social Anthropology. Essays in memory of E.E. Evans-Pritchard by his former Oxford colleagues. J.M. Beattie e R.G. Lienhardt (orgs.), Oxford University Press, 1975
} 
DUMONT, Louis. 1971. Introduction à deux theories d'anthropologie sociale: groupes de filiation et alliance de mariage. Paris-Haia: Mouton.

EVANS-PRITCHARD, Evans E. 1951. Social Anthropology. Londres: Cohen \& West.

FORTES, Meyer. 1953. "The Structure of Unilineal Descent Groups". American Anthropologist, vol. 55: 17-41.

LEACH, Edmund. 1961. Pul Eliya, a village in Ceylon: a study of land tenure and kinship. Cambridge: Cambridge University Press.

MAUSS, Marcel. 1896. "La Religion et les Origines du Droit Pénal” (resenha da obra de Steinmetz). Revue de l'Histoire des Religions, vol. 34: 269-95

POCOCK, David. 1961. Social anthropology. Londres e Nova Iorque: Sheed a. Ward

SMITH, M. G. 1956. "Of segmentary lineage systems”. Journal of the Royal Anthropological Institute, vol.86, n. 2: 39-80.

sobre o autor

sobre a tradutora

\section{Louis Dumont}

Professor da Universidade de Oxford e diretor de estudos da École de Hautes Études en Sciences Sociales, membro da Academia Britânica e da Academia de Artes e Ciências dos Estados Unidos.

\section{Beatriz Perrone-Moisés}

É professora associada do Departamento de Antropologia da Universidade de São Paulo.

Contribuição de Autoria: Não se Aplica

Financiamento: A produção deste artigo não contou com financiamento à pesquisa.

Recebido em 05/10/2021

Aceito para publicação em 08/12/2021 